\title{
Late life Depression: \\ Prevalence, Pathogenesis, Clinical Presentation, Evaluation and Emerging Therapeutics
}

\section{Hany I. Hassanin, MD}

\author{
Geriatrics and Gerontology, Faculty of Medicine, Ain Shams University, Egypt. \\ Correspondence: $\underline{\text { h.ibrahim.ger@gmail.com }}$
}

Depression is the prototype of mood disorders in older adult, however; it is not a feature of normal ageing, and rather it is a painful emotional experience characterized by loss of interest or pleasure in life enough to cause functional impairment. ${ }^{(1)}$ It is a major public health problem; and a common cause of emotional distress and poor quality of life among older adults. Depression increases the perceived disability of comorbid physical illnesses. Moreover, it is associated with increased all- cause mortality. ${ }^{(2)}$

The clinical symptoms and causes differ considerably between elderly who are diagnosed with depression late in life and patients who experience a recurrence of preexisting illness late in life. ${ }^{(3)}$ However, there is no consensus regarding the age used to differentiate between the late- and early-onset depression. In the USA 50 years of age is the used cut off and in UK the age of 60 is the used one. ${ }^{(4)}$

\section{Prevalence of depressive disorders among elderly:}

The prevalence of depression among elderly varies according to the used diagnostic criteria. Indeed, depression is a group of different clinical entities. The depressive disorders listed in the Diagnostic and Statistical Manual of Mental Disorders, 5th editions (DSM-V) can be distinguished from one another by different symptoms and signs. The depressive disorders include major depressive disorder, dysthymic disorder, bipolar disorder and mood disorder due to a general medical condition. Adjustment disorder with depressed mood may also be considered a form of depression. (5) For community dwelling elderly, the prevalence of major depression ranges from $1 \%$ to $5 \%$. The other depressive symptoms are present in $15 \%$ of the elderly in the community setting. Rates of depression are higher in older women than in older men, but this gender gap disappears among the oldest old. Rates of major depression among older adults are higher in other settings e.g. medical outpatients (5$10 \%)$, medical inpatients (10-12\%), and residential care facilities (14 to $42 \%)$. ${ }^{(6)}$

\section{Risk factors of late life depression:}

Complex biological, psychological, and social factors are linked to the development of depression among older adults. ${ }^{(7)}$

\section{Genetics}

Genetic susceptibility to depression in late life (DLL) is an attractive theory that explains why some older persons are predisposed to depression. But specific genetic markers for late onset type have not been identified yet. On the other hand, genetic factors are found to play a great role in the development of the early onset depression in elderly. These factors include the serotonin transporter (5HTTLPR) gene, apolipoprotein E (ApoE) gene, brain-derived neurotrophic factor (BDNF) gene, and 5methylenetetrahydrofolate reductase (MTHFR) gene. Moreover, these genes may be involved in the treatment response of depression in later life. ${ }^{(7)}$

\section{Non-genetic biological risk factors:}

These biological risks include endocrine, inflammatory or immune, cardiovascular, and brain circuits' factors. (6)

\section{a) Link between immune system and DLL}

Several studies focused on acquired immune responses in patients suffering from depression (e.g., T- and Bcell functions, which were generally found to be suppressed), more recent research suggests that a significant percentage of depressed patients may experience activation of the innate immune response. (8-10)

A marked breakthrough in terms of the recognition of the potential contribution of immunity to depression has been demonstrated that all cardinal features of inflammation are apparent in patients with major 
depression. Elderly with late life depression have been found to exhibit significant elevations of innate immune cytokines and their soluble receptors not only in peripheral blood but also in cerebrospinal fluid (CSF). Also, they exhibit elevations in acute-phase reactants, chemokines, and adhesion molecules as well as inflammatory mediators such as the prostaglandins. (11)

A meta-analysis had been conducted and indicated that inflammatory markers elevations like IL-6 and CRP were linked to more association with depressive symptoms. ${ }^{(12)}$ Additionally, correlations between the severity of depressive symptoms and increased peripheral inflammatory cytokines have been observed. ${ }^{(13)}$ However, the link between inflammatory markers and specific behavioral changes is still under investigation, it should be noted that easy fatigue, loss of energy, and psychomotor retardation are some of the most common symptoms after cytokine administration. ${ }^{(14,15)}$

\section{b) Neurotransmitter Dysfunction and DLL}

Dysfunction in serotonergic, noradrenergic, and dopaminergic neurotransmission has been demonstrated in DLL. Evidence exists that the agerelated changes of the neurotransmitters make older persons more susceptible to depression. It is a fact that the antidepressant medication targeting serotonin and noradrenaline function improves depressive symptoms. (7)

\section{c) The Role of Stress}

Abnormalities of the HPA axis in depressed patients are well described. Overt dysregulation is found only in a subset of depressed patients. As articulated by Nemeroff and his colleagues depression and early psychological trauma converge at the level of HPAaxis regulation. ${ }^{(16)}$ Adversity that occurs early in life specially if severe and/or prolonged seems to contribute significantly both to subsequent risk for anxiety and depressive disorders and to HPA dysfunction. Physical, psychological, sexual abuse traumas or the loss of beloved person that occur during critical periods of development result in a permanent alteration of stress reactivity in the central nervous system with subsequent increased vulnerability to later psychiatric disorders. (17)

Actually, the maintenance of activated stress response system following chronic or severe stress makes adaptive sense and high threat intensity resulting in persistent elevated "alert' status. This stress reactivity could explain the findings of high levels of HPA-axis activity, including elevated peripheral cortisol $(18,19)$ and central corticotrophin-releasing hormone ${ }^{(20,21)}$ in some depressed elderly.

\section{d) Brain circuits and DLL}

Dysfunction of certain areas or circuits of the brain are related to the development and the prognosis of DLL. These areas include the dorsolateral prefrontal cortex, orbitofrontal cortex, anterior cingulate cortex, subcortical white matter, basal ganglia (especially striatum), and the hippocampus. ${ }^{(7)}$

Regional cerebral blood flow and cerebral metabolism studies have demonstrated that the dorsal cingulate gyrus, middle and dorsolateral prefrontal cortex (DLPFC), insula, and superior temporal gyrus are all hypoactive at rest during negative mood states and that their activity increases with selective serotonin reuptake inhibitor treatment. ${ }^{(22)}$

\section{e) The Bidirectional Relationship Between Depression And Comorbidities}

There is no doubt that advanced aging carries a high probability of other medical and/or psychiatric disorders. Depression as one of the most common psychiatric illnesses in elderly population has a unique bidirectional relation with other comorbid conditions including prevalence, prognosis, and response to standard medications or even selection of pharmacotherapy.

Almost any serious or chronic condition can produce a depressive reaction; the disorders that are most strongly associated with depression include cardiac conditions and neurologic illness, including cerebrovascular disease. Specific medical conditions that may be associated with geriatric depression include myocardial infarction, coronary heart disease, cardiac catheterization, diabetes, and obesity. ${ }^{(7)}$

Nemeroff and Owens (23) summarized the biologic underpinnings of depression and categorized this into 3 general systems of altered function: the monoamine neurotransmitter systems, the cardiovascular system and disturbance in the hypothalamic-pituitary-adrenal (HPA) axis. These systems are also involved in various common medical disorders.

Now we will review few examples about some commonly distributed medical problems in elderly and its interaction with late life depression.

\section{Late-Life Depression and Cardiovascular Disorders in Older Adults.}

In the last five decades, many studies have revealed a link between the incidence of depression and cardiovascular morbidity and mortality. Even after controlling for other possible confounders, like age, smoking and other behavioral and medical cofactors, depression appears to increase the risk for ischemic heart diseases (by 1.5-fold to 2.0-fold), as well as 
death from cardiac diseases. (24) The severity of depression has consistently been shown to predict sequels, readmission, increases the frequency of cardiac events and negatively correlates with the functional benefits from coronary artery bypass grafting. ${ }^{(25)}$

Moreover, many Studies have indicated surprising results that $16 \%$ to $18 \%$ of admitted patients after an acute myocardial infarction (AMI) are prone to major depression, and about $30 \%$ of them experience depression during the first 12 months after infarction, especially in the first 6 months. ${ }^{(26)}$ Major depressive disorder has been associated with increase mortality by 3.5 -fold in the first 24 weeks following an AMI, and 2.0 -fold over 6.7 years of follow-up. ${ }^{(27)}$

\section{Late-Life Depression and Common Endocrinal Disorders}

Endocrine system undergoes multiple age related changes that could contribute to multiple psychological and behavioral disturbances. Several studies indicated that subclinical hypothyroidism can be present in about $23 \%$ of the elderly. Many cases of subclinical hypothyroidism pose variable degrees of depressive symptoms either de novo or exacerbation of preexisting symptoms. ${ }^{(28)}$

Many symptoms of depression in later life could be bidirectional, with age-related endocrine changes, such as low serum levels of estrogen or testosterone. However, more than $70 \%$ of men above 70 years have free levels of testosterone consistent with hypogonadism. (29) Low testosterone in men is associated with depression, fatigue, hot flushes, sweating, and weight gain, as well as, low muscle mass, increased fat mass, low muscle power, anemia, and osteoporosis. ${ }^{(30)}$

\section{Late-Life Depression and medications:}

Many drugs are associated with depressive disorders (such as beta blockers, CNS medications, calcium channel blockers, digitalis, corticosteroids, hormones, anti-Parkinson agents, respiratory or gastrointestinal medications, certain cancer medications, benzodiazepines and interferon). ${ }^{(6)}$

\section{Late-Life Depression and Chronic Obstructive Pulmonary Disease}

Depression frequently coexists with COPD, with prevalence of comorbid depression varying from $10 \%$ to $42 \%$, with the highest prevalent of depression in those who are on domiciliary oxygen. ${ }^{(31,32)}$ However, comorbid depression is frequently associated with lower physical activity, lower compliance to medications, increased hospital admission and mortality, dyspnea, easy fatigability, and disability in those with COPD, even after adjustment of severity of illness. ${ }^{(31)}$
More than $80 \%$ of patients with COPD are smokers, and smokers are more likely to either restart smoking or heavily smoke during periods of exacerbation, which in turn may worsen respiratory status. Increased risk of alcohol abuse by depressed patients with COPD may put such patients at increased risk of severe community-acquired pneumonia, particularly aspiration pneumonia. ${ }^{(33)}$

Many patients with COPD who developed depressive symptoms passed undiagnosed because of several causes such as limited awareness by both patients and health care providers of this comorbidity; limited resources, time during provider visits; and misinterpretation of depressive symptoms as symptoms of COPD. (34)

There is a big challenge in this issue as symptoms of depression and COPD widely overlap and special attention must be taken to avoid mistaking symptoms of depression and worsening of COPD and vice versa, but sustained depressed mood or anhedonia should not be attributed to lung disease alone. Indeed, Loss of energy, memory impairment and lack of concentration, weight loss, and sleep disturbances can be common symptoms in either depression or COPD. ${ }^{(31)}$

\section{Relationship of late-life depression and cognitive impairment}

Memory impairment and depression were linked in many previous studies, the cognitive impairment related to depression was thought to be reversible, and now evidence suggests the presence of longer-lasting effects. ${ }^{(35)}$

Moreover, $40 \%$ of individuals developed late onset major depression with cognitive impairment are at risk of developing AD within three to five years. ${ }^{(36)}$

Symptoms of depression are usually present in dementia and may occur in $(40 \%-50 \%)$ of patients with AD. It occurs more commonly as a symptom in vascular dementia than in Alzheimer dementia. ${ }^{(35)}$

\section{Relationship of late-life depression and Neurologic disorders}

The prevalence of depressive disorders is high among elderly patients suffering from cerebrovascular disease and other neurologic disorders. The prevalence rate for major depression is $19.3 \%$ among hospitalized patients and $23.3 \%$ in outpatients with stroke. ${ }^{(35)}$

The prevalence of major depression varies from $7.7 \%$ to more than $25 \%$ in outpatient samples with PD. Other depressive symptoms occur in approximately half of the patients with PD causing substantial functional impairment. (37)

Depression in PD is not a reaction to psychosocial stress and disability. It is secondary to the underlying neuroanatomical degeneration, leading to changes in the central serotonergic function and in neurodegeneration of specific cortical and subcortical 
pathways. ${ }^{(38)}$ Depression in PD is usually mild and less frequently associated with dysphoria, anhedonia, feelings of guilt, and loss of energy but is associated with more concentration problems than depression in older adults without neurologic disease. (39)

\section{Psychosocial Factors and Personality}

Many psychological factors are associated with depression. Neuroticism is a personality trait characterized by worry, fear, anxiety, guilt, and moodiness. People with a high level of neuroticism can be prone to DLL. While, high levels of mastery of one's environment and self-efficacy provide protection against DLL ${ }^{(7)}$ as shown in table (1).

Aging is associated with progressive losses including withdrawal from work, loss of purpose, reduced independence, loss of friends, increased poverty, the risk of developing an illness leading to learned helplessness, and subsequently occurrence of DLL. (35)

Table 1: Contributors to late life depression

\begin{tabular}{|rl|}
\hline \multicolumn{1}{|c|}{ Biological risks } \\
\hline 1. & Genetic susceptibility - female sex \\
\hline 2. & $\begin{array}{l}\text { Under activity of serotonergic, } \\
\text { noradrenergic neurotransmission }\end{array}$ \\
\hline 3. & Dysregulation of HPA axis \\
\hline 4. & $\begin{array}{l}\text { Hypogonadism, excess cortisol, and } \\
\text { hypothyroidism }\end{array}$ \\
\hline 5. & Acute phase reactant \\
\hline 6. & Vascular diseases \\
\hline 7. & Dementia \\
\hline 8. & Other medical conditions (COPD, DM,.., $)$ \\
\hline 9. & Other neurological conditions (stroke, \\
& PD,....) \\
\hline 10. & $\begin{array}{l}\text { Medications (beta blockers, CNS } \\
\text { medications, calcium channel blockers, } \\
\text { digitalis, corticosteroids,.........) }\end{array}$ \\
\hline Psychosocial risks \\
\hline 11. Neuroticism \\
\hline 12. learned helplessness \\
\hline 13. Cognitive distortions \\
\hline 14. External locus of control \\
\hline Social risks \\
\hline 15. Stressful life events and daily hassles \\
\hline 16. Bereavement \\
\hline 17. Socio-economic disadvantage \\
\hline
\end{tabular}

\section{Symptomatic Differences in the Elderly:}

The Diagnostic criteria for different types of mood disorders are the same for the elderly and the young, however; symptom expression can be age dependent. (41)

Depressed mood, which is the cardinal symptom of depression, may be less prominent in depression in old age making early recognition of late-onset depression difficult for health care providers. ${ }^{(2)}$

Early onset depression is usually characterized by longer duration of symptoms, a personal history of depressive episodes, a serious suicide attempt, childhood events, a family history of depression, and high neuroticism. On the other hand, the late onset depression is usually associated with poor appetite, weight loss, psychomotor change, anhedonia and cognitive deficit. ${ }^{(40)}$

Vascular depression usually presents with apathy, psychomotor retardation, poor executive function, less depressive thinking (such as guilt or unworthiness), and a late age at onset. ${ }^{(2)}$

Compared to young patients, elderly people with new or recurrent depression are more hypochondriacal, delusional, and tend to present more with symptoms of psychomotor change, anhedonia, cognitive impairments. ${ }^{(40}$

The terms "masked depression" and "depressive equivalents" are sometimes used to describe older patients who do not appear depressed but manifest physical symptoms such as chronic pain, fatigue, or hypochondriasis. ${ }^{(41)}$

There is a higher incidence of minor depression than major depressive disorder in the elderly.

\section{Suicidal behavior in DLL:}

There is an age related rise in the rate of suicide in patients with depression. Moreover, a suicidal attempt can be the initial presentation of DLL. Increased risk of suicide may be related to multiple chronic medical conditions, insomnia, and lack of social support. As with patients of all ages, worsening suicidal ideation may indicate hospitalization and ECT. ${ }^{(3)}$

\section{Sleep and DLL:}

Major depression at any age is associated with sleep problems both insomnia and hypersomnia, however, aging itself increases the prevalence of insomnia. Insomnia is a risk factor for first and recurrent episodes of depression. Early morning awakening is common in older depressed patients. ${ }^{(3)}$

Ageing is associated with phase advance in the restactivity cycle. Starting from the third decade, the sleeping period starts earlier. Among depressed patients with insomnia, the midpoint of the sleep period advances 4 minutes earlier for each year of age. Treating the sleep problems in DLL should focus on an earlier bedtime and an earlier rising time. (3)

\section{Who Should Be Screened for Depression?}

The U.S. Preventive Services Task Force (USPSTF) supports depression screening in primary care settings for adults, including older adults, if there is adequate treatment with antidepressants, therapy or a combination of both available. ${ }^{(42)}$

Many validated tools exist for initial depression screening in later life e.g. The PHQ-9 and GDS. Full psychiatric evaluation should be performed for those screened positive for depression ${ }^{(43)}$ as described in table (2) for diagnostic criteria of DLL. 
Table 2: Diagnostic criteria of depression according to DSM-5 and ICD-10

\begin{tabular}{|c|c|c|}
\hline & DSM-5 & ICD-10 \\
\hline \multirow{4}{*}{$\begin{array}{l}\text { Core } \\
\text { symptoms }\end{array}$} & Depressed mood & Depressed mood \\
\hline & Loss of interest or pleasure & Loss of interest or pleasure \\
\hline & & Decreased energy or increased fatigability \\
\hline & & Decreased energy or increased fatigability \\
\hline \multirow[t]{7}{*}{$\begin{array}{l}\text { Other } \\
\text { symptoms }\end{array}$} & $\begin{array}{l}\text { Weight loss or weight gain, increased } \\
\text { or decreased appetite }\end{array}$ & $\begin{array}{l}\text { Decreased or increased appetite with } \\
\text { corresponding weight gain }\end{array}$ \\
\hline & Insomnia or hypersomnia & Sleep disturbance of any type \\
\hline & Psychomotor agitation or retardation & Psychomotor agitation or retardation \\
\hline & Fatigue or loss of energy & Loss of confidence and self-esteem \\
\hline & $\begin{array}{l}\text { Feelings of worthlessness or excessive } \\
\text { or inappropriate guilt }\end{array}$ & $\begin{array}{l}\text { Unreasonable feelings of self-reproach or } \\
\text { excessive and inappropriate guilt }\end{array}$ \\
\hline & $\begin{array}{l}\text { Diminished ability to think or } \\
\text { concentrate or Indecisiveness }\end{array}$ & Diminished ability to think or concentrate \\
\hline & $\begin{array}{l}\text { Recurrent thoughts of death, suicidal } \\
\text { ideation, attempt, or plan }\end{array}$ & $\begin{array}{l}\text { Recurrent thoughts of death or suicide or suicidal } \\
\text { Behavior }\end{array}$ \\
\hline
\end{tabular}

\section{Management of late life depression}

The first priority in treating elderly with depression is starting a plan to keep patient safe, which means evaluating presence of suicidal thoughts and any previous attempts to commit suicide. If there is positive history about ending his/her life, then interferences to prevent suicide must be applied, including strong family support and ensure safety of surrounding environment via remove weapons or stockpiles of drugs. ${ }^{(44)}$ Prevalence of suicidal ideation and attempts are higher in later life than in younger age groups $\cdot(1)$

Table 3: Lines of Management of Late Life Depression

\begin{tabular}{|c|}
\hline Non Pharmacological Treatment: \\
$>$ Psychotherapy \\
$>$ Alternative And Complementary \\
$\quad$ Medicine \\
$>$ Electroconvulsive Therapy \\
$>$ Tai Chi \\
\hline Pharmacological Treatment: \\
$>$ Standard Treatment \\
$>$ Emerging Therapeutics \\
\hline
\end{tabular}

\section{Non Pharmacological Management i. Psychotherapy}

Evidence-based guidelines for treatment of moderate to severe depression in older adults recommend antidepressants and psychotherapy as the first-line of treatment (45). The American Psychiatric Association reported that $52 \%$ of health care providers used a combination of standard medication and psychotherapy while, $39 \%$ of them reported prescription of medication only ${ }^{(46)}$

Many studies reported that older adults prefer psychological treatment compared to pharmacologic treatments ${ }^{(47)}$ and a recent meta-analysis reported that psychotherapy may be more beneficial than antidepressants for older adults with dysthymia or subsyndromal depression ${ }^{(48)}$.

\section{ii. Cognitive therapy}

Cognitive behavioral therapy was first developed by Beck in 1976 and recently many health care providers consider cognitive behavioral therapy one of the most important non pharmacological lines of management of depression as shown in table (3). It was built on the theory that how we interpret situations influences our mood and behaviors. Management techniques are designed to allow individuals to recognize maladaptive or distorted cognitions and learn to encounter them so as to diminish strength of emotion and challenging behaviors. Behavioral therapy for depression is grounded on the concept that depressed individuals involve in few pleasurable and/or mastery events and thus do not obtain reinforcement from their environment ${ }^{(49)}$.

\section{iii. Alternative and complementary medicine}

Elderly patients are chiefly vulnerable to antidepressant adverse effects, such as gastritis, sedation, dry mouth and sexual dysfunction (50). Many older patients prefer alternative therapy and may be resistant to taking antidepressants because of stigma about mental disorders. ${ }^{(51)}$ 


\section{a) Fish oil and omega 3}

The omega-3 fatty acids, derived from fish oil, have also been widely studied in affective disorders, with more than 30 published clinical trials ${ }^{(52)}$. Studies seem to support antidepressant efficacy, both as monotherapy and as augmentation of standard antidepressants.

Recommended doses for depression based on clinical trials are roughly $1000 \mathrm{mg} / \mathrm{d}$. There is at least one published clinical trial examining the omega-3 fatty acids in depressed elderly. Rondanelli and colleagues $2010^{(53)}$ carried out an 8-week, randomized, doubleblind, and placebo controlled trial of an omega-3 preparation $(2.5 \mathrm{~g} / \mathrm{d})$ against placebo in 46 depressed female nursing home residents, ages 66 to 95 . The investigators found a significant Improvement in depressive symptoms as well as in health related quality-of-life symptoms in the omega-3 group compared with the placebo group.

\section{b) Folic Acid}

There is accumulating evidence about association between depressive symptoms and low serum levels of folate (54). Multiple studies have examined different folic acid forms for antidepressant like effect predominantly in combination with standard agents, with promising results $(55,56)$. The 5-MTHF (Deplin) was studied as an antidepressant adjunct therapy at doses of $15 \mathrm{mg} / \mathrm{d}$. This form may be principally effective because it can cross the blood-brain barrier directly and deliver more active product.

\section{c) Exercise}

There is no doubt that, health benefits of regular physical exercise have long been known and scientifically supported for a variety of populations (57). Higher physical activity levels among elderly specifically may have a protective effect against development of depression ${ }^{(58)}$. Recent results point to the potential usefulness of exercise as a treatment of depressive symptoms in older adults, in certain cases with similar efficacy to antidepressants. The design of exercise (ie, supervised or unsupervised) may be an important variable to be consider ${ }^{(59)}$. Timonen and colleagues in 2002 compared supervised anaerobic exercise (ie, strength training) twice per week with unsupervised home-based exercise 2 to 3 times per week. Depressive symptoms were significantly reduced $(\mathrm{P}$ value $=0.048)$ for Members in the supervised exercise group compared with those in the unsupervised arm, suggesting that adherence to exercise regime, social support, or both may facilitate the effects of exercise on depressive symptom ${ }^{(60)}$.

\section{Pharmacological Treatment :}

In the beginning of $1950 \mathrm{~s}$, the most effective antidepressants were classified into monoamine oxidase inhibitors and tricyclic antidepressants. These medications could improve affect in more than half of depressed patients after a few weeks of adherence. Almost all recent antidepressants were industrialized via minor modifications of original antidepressants act chiefly through mono-aminergic mechanisms.

On the other hand, recent technology made marked reduction in side-effect profiles and overdose toxicity but these newer medications did not show significant difference in the efficacy and/or speed of its effect.

\section{Standard Treatment}

Most of the reviews did not find a discrepancy between different classes of antidepressants in elderly (61). However, in many studies directly comparing between TCAs and SSRIs, there was no difference in the efficacy profile. Unfortunately, most of these trials have been supported by a pharmaceutical company and presence of conflict of interest. In addition to that there is no concrete conclusion about which SSRI member should be the treatment of choice for depressed elderly.

This is may be due to the equal side-effect profile of all SSRIs with little differences in drug-drug interactions as shown in table (4). Nortriptyline is a secondary amine which exhibit less orthostatic hypotension adverse effect than tertiary amines (e.g., amitryptiline) and is the TCA of choice in treating late life depression.

The usage of TCAs became more limited since SSRIs and other antidepressant explicit better safety profile. The main safety issue of TCAs is their serious cardiovascular side effect, including higher risk of sudden cardiovascular death especially if concomitant ischemic heart disease is present in addition to high mortality rate after an overdose. TCAs are not recommended as the first choice of treating depression in elderly. There are many anticholinergic adverse effects of TCAs including dry mouth, urinary retention, and cognitive impairment. So, orthostatic hypotension is problematic in elderly because of its higher risk of falls and other serious consequences that increases the overall morbidity and mortality but if there is a strong indication to continue the antidepressant ${ }^{(62)}$.

Table 4: Common classes of antidepressant

\begin{tabular}{|l|l|l|l|}
\hline Medication & Dose & Sedation & $\begin{array}{l}\text { Anti- } \\
\text { cholinergic }\end{array}$ \\
\hline Fluoxetine & $5-20 \mathrm{mg}$ & + & + \\
Sertraline & $25-100 \mathrm{mg}$ & + & + \\
Paroxetine & $10-20 \mathrm{mg}$ & + & ++ \\
Citalopram & $10-40 \mathrm{mg}$ & + & + \\
\hline Nortriptyline & $10-75 \mathrm{mg}$ & +++ & +++ \\
Desipramine & $25-125 \mathrm{mg}$ & ++ & ++ \\
\hline Mirtazapine & $15-45 \mathrm{mg}$ & +++ & + \\
Trazodone & $50-300 \mathrm{mg}$ & ++++ & + \\
Bupropion & $75-150 \mathrm{mg}$ & + & + \\
Venlafaxine & $25-75 \mathrm{mg}$ & + & + \\
\hline
\end{tabular}




\section{Emerging therapeutics:}

\section{Glutamatergic Drugs}

There is accumulating evidence suggesting that alterations in the glutamatergic neurotransmitter system participate in the neurobiology of major depressive disorder (MDD) ${ }^{(63,64)}$

In animal studies, there is several reports that stress is associated with higher levels of glutamatergic activation in numerous brain regions ${ }^{(65)}$ contributing to various form of stress-related neurotoxicity ${ }^{(66) .}$

In vivo magnetic resonance spectroscopy studies have established abnormal Glu content in various brain regions of patients with MDD (67). For all these reasons, there is increased desire to synthesize pharmaceutical agents targeting the glutamatergic system for the treatment of MDD. The NMDA receptor has acquire significant attention All through the field of neuroscience because of its roles in learning neurotoxicity and Neuroplasticity. The receptor has numerous unique properties, such as the need for a coagonist (glycine), the presence of multiple allosteric binding sites, a voltage sensitive blockage of the ion channel by magnesium and interactions with various scaffolding proteins that mediate the transport and localization of the receptor as well as interactions with multiple signaling, which make it well suited to playing a critical role in regulating neuroplastic changes.

An early report in this area by Skolnick ${ }^{(68)}$ suggested that the receptor may be a target of antidepressant action by showing that a drug's ability to alter the NMDA receptor's binding affinities was greatly associated to its antidepressant activity in the outpatient clinic. Interest in the NMDA receptor grew quickly after the unexpected finding that single subanesthetic dose $(0.5 \mathrm{mg} / \mathrm{kg}$ over 40 minutes $)$ of ketamine which is noncompetitive NMDA receptor antagonist, created a rapid and sustained response in 7 individuals with previously treatment as resistant MDD ${ }^{(69)}$.

Although this promising results of these studies that explore potential development of NMDA antagonists as antidepressant agents, ketamine produces several acute adverse effects, such as disturbed consciousness, perceptual and cognitive alteration and increased blood pressure, that markedly limit its potential usefulness in the outpatient care system including the intravenous route of administration.

On the other hand, the finding that ketamine produces a rapid Mood Improvement after a single does not essentially mean that chronic administration will sustain the response. In fact, it is possible that chronic administration of NMDA antagonists could have damaging properties on neuronal survival. ${ }^{(70)}$

\section{II. mGluR Drugs}

Group II metabotropic receptors (mGluR2 and mGluR3) are principally present on the presynaptic membrane in addition to glial cells, where they are supposed to modulate Glu neurotransmission by sensing Glu Spillover and regulating transmitter release. Recent study has suggested that the group II metabotropic receptors also provide a vital role in the mechanisms of neuroprotection and neurodegeneration (71). The role of the $\mathrm{mGlu} 2 / 3$ receptors in controlling Glu neurotransmission makes them extremely motivating targets for antidepressant drug advance, and rapidly accumulating evidence advocates that drugs targeting the mGluR2/3 receptors exhibit both antidepressant and anxiolytic properties (72),(73). Riluzole (Rilutek), a drug currently Food and Drug Administration-approved and marketed for the treatment of amyotrophic lateral sclerosis, (74) has gained considerable attention. Riluzole (2-amino-6trifluoromethoxy benzothiazole) appears to modulate Glu neurotransmission by numerous pharmacological mechanisms. The drug was originally developed as an anticonvulsant, and early studies showed it to oppose several actions of Glu in vitro and in vivo ${ }^{(75)}$.

Following an initial case report of a patient with comorbid obsessive compulsive disorder and MDD who appeared to experience a clinical benefit in both mood and obsessive-compulsive disorder symptoms after starting riluzole, (76) there have been several additional reports of open-labeled clinical trials suggesting that riluzole possesses potent antidepressant and anxiolytic properties.

An initial open-label clinical trial investigative the effects of riluzole in 19 treatment-resistant depressed patients found a major improvement in mood evaluations beginning in the third week of treatment (77).

A more recent study demonstrated that riluzole augmentation of traditional antidepressant medications produced a significant improvement in depressive symptoms in 10 subjects with severe treatmentresistant depression (78). Moreover, subjects who achieved a remission in the initial 6-week phase of this study sustained their remission for the 3-month duration of the study.

\section{Melatonin:}

Melatonin, a tryptophan-derived hormone released chiefly from the pineal gland, is a vital regulator of sleep/wake cycles (79). Also, melatonin release is synchronized to a 24-hour cycle via light exposure ${ }^{(80) \text {. }}$

Apart from sleep disturbance associated with depression, it is not astonishing that melatonin has been greatly examined in depression research. Both the concentration of melatonin and the timing of melatonin release are disturbed in depression (81). Additionally, close adherence to antidepressants medications results in increased melatonin levels ${ }^{(80)}$.

In general, the administration of melatonin itself has not shown consistent efficacy in major depression (82). This disappointing result has increased interest in the use of agomelatine, a melatonin receptor agonist. Like familiar antidepressants, prolonged agomelatine treatment results in increased hippocampal neurogenesis (83). 
Loo and colleagues in 2002 conducted a double-blind, placebo-controlled trial of agomelatine including 711 patients with MDD and found that $25 \mathrm{mg}$ of agomelatine was significantly more effective than placebo. A second double blind, placebo-controlled trial confirmed the efficacy of agomelatine, and a pooled analysis confirmed the overall effect ${ }^{84)}$ Together, these findings have raised substantial hope that agomelatine will prove to be an effective antidepressant, possibly with a faster onset of action than current antidepressants. It is important to note that the long-term efficacy and tolerability of agomelatine have not yet been reported.

\section{Triple reuptake inhibitors}

After the established success of the serotoninnorepinephrine reuptake inhibitors (SNRI) in treatment of MDD, researchers have tracked the idea of developing one agent that can block all three monoamine transporters, the so-called 5-HT, NE, DA reuptake inhibitors (SNDRIs), or triple reuptake inhibitors.

This hypothesis was based on the positive role of DA on the reward system and the fact that anhedonia is a prominent symptom in a subset of MDD patients ${ }^{(85) .}$ This theory was further reinforced by positive clinical augmentation studies with DA-enhancing drugs ${ }^{(85) \text {. }}$

During the past decade, several SNDRI drug members have been tested in the clinic. The main worries with these drugs were how to avoid excessive dopaminergic stimulation and possibility of drug abuse.

Amitifadine (DOV-21947 or EB- 1010), which was among the first SNDRI drug candidates, preferentially enhanced 5-HT with 1:2:8 potency rankings for the inhibition of SERT, NET, and DAT, respectively (86). Amitifadine showed efficacy in a small clinical proof-ofconcept (PoC) study. However, amitifadine did not meet the clinical endpoint in a subsequent larger double-blind placebo-controlled study in MDD patients who had failed one treatment with a first-line antidepressant.

Extra clinical studies in MDD are being planned with this compound at higher doses. Other efforts to develop more balanced SNDRIs with similar Ki values for SERT, NET and DAT have also failed, in most cases before reaching PoC studies.

Two compounds, NS-2359 (GSK-372475) and liafensine (BMS-820836), were evaluated in phase 2 clinical studies, but unfortunately both programs were terminated. In a large phase 2 program with 900 patients, NS-2359 was found neither efficacious nor well tolerated, whereas comparators venlafaxine and paroxetine separated significantly from placebo ${ }^{(87) .}$

Thus, in spite of significant investments, the clinical value of SNDRIs for the treatment of depression remains to be demonstrated. There are still several SNDRIs in preclinical development (e.g. LPM570065) ${ }^{(88)}$ that might be clinically tested at a later time. However, the disappointment of the DA-releasing compound lisdexamfetamine to show efficiency as adjunctive therapy in MDD patients who responded insufficiently to monotherapy with an SSRI or SNRI is not helpful of a role of enhanced DA transmission in promoting antidepressant property. SNDRIs might have better efficacy in a well-defined subset of MDD patients with prominent symptoms of anhedonia. This remains to be substantiated in future clinical studies.

\section{Anticholinergic mechanism}

Another cholinergic mechanism that has been revealed for the treatment of MDD depended on the modulation of nicotinic cholinergic receptors (89). Both nicotinic antagonists and partial agonists have been tested in clinical trials, but with limited success. A clinical study of the a4b2 nicotinic cholinergic receptor antagonist TC5214 (the S-enantiomer of mecamylamine) as an add-on treatment to SSRIs was promising, but unfortunately the further clinical studies were unsuccessful to explore this result and the development program was aborted ${ }^{(90)}$.

\section{Opioid antagonists}

Another approach that has recently obtained substantial interest is kappa opioid antagonists. Increase of dynorphin release, the endogenous ligand for the kappa opioid receptor, has been found to cause dysphoria in humans after chronic stress exposure. Furthermore, preclinical studies have verified that dynorphin can reduce dopamine release in the nucleus accumbens and thereby cause anhedonia-like symptoms ${ }^{(91)}$.

ALKS-5461, a combination of buprenorphine (partial m opioid receptor agonist, kappa opioid receptor antagonist) and samidorphan ( $\mathrm{m}$ opioid antagonist), has shown optimistic results in a phase 2 study and is currently in phase 3 as an augmentation therapy for the treatment of TRD (https://clinicaltrials.gov/show/NCT02158533)

\section{Neuro-inflammation :}

Another biology linked to MDD is the chronic elevated inflammatory cytokines, has been an area of interest for some time. The interest has been powered by numerous studies signifying that depressed patients have elevated serum levels of pro-inflammatory cytokines, notably IL-6 and TNF- $\alpha^{(92) \text {. }}$

Cyclooxygenase-2 (COX-2) inhibitors that decrease production of prostaglandine $\mathrm{E}_{2}$ and pro-inflammatory cytokines have been examined in a number of clinical trials of MDD. The frequently tested drug celecoxib, exposed antidepressant efficacy as an add-on therapy to reboxetine ${ }^{(93)}$ fluoxetine ${ }^{(94)}$ and sertraline in three small double-blind placebo controlled trials.

In single study, the adjunctive therapy with celecoxib reduced IL- 6 blood levels in depressed patients, and there was a substantial correlation between the decrease in Hamilton Depression Rating Scale scores and IL-6 serum levels after six weeks of treatment (95). In preclinical study, celecoxib was shown to augment the effects of reboxetine and fluoxetine on cortical NE and 5-HT levels in rats which might afford mechanistic support for its antidepressant efficacy ${ }^{(96)}$.

In addition to combined treatments with COX-2 inhibitors, the potential of a TNF- $\alpha$ antibody as 
monotherapy has been evaluated in TRD patients in one clinical trial (97).

In that study, the TNF- $\alpha$ antibody, infliximab, did not differ from the placebo, but did show a trend toward antidepressant activity in patients with elevated levels of

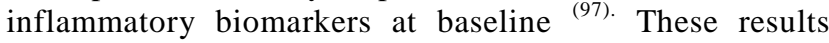
indicate that anti-inflammatory agents should be further examined as treatment options for MDD, especially in patients with comorbid inflammatory diseases and high levels of inflammatory cytokines.

\section{Prognosis}

DLL leads to multiple negative consequences, such as disability, cognitive impairment, deterioration in comorbid physical disorders, and an increased risk of mortality. Remission rates of DLL after treatment is similar to that of younger age groups; however, relapse rates are higher. The risk of relapse is highest for the first 6 months. Hence, treatment should be continued for 6-9 months. (7)

Even after the first depressive episode in old age, the relapse rate is high after the treatment has been discontinued. So, lifelong maintenance treatment is recommended even if the first depressive episode has a later onset for severe cases. Cautions regarding polypharmacy, side effects, and other risk factors for relapse, such as cerebrovascular pathology, other physical diseases, and cognitive impairment should be considered. (7)

\section{Summary:}

DLL is a common problem in geriatrics clinic. It is usually underreported and under recognized due to atypical signs and symptoms of depression. DLL is attributed to complex bio-psychosocial factors. Initial screening, followed by a more thorough physical examination and mental health interview, should be the mainstay of geriatric clinicians' practice. Different modalities of therapy should be considered based on efficacy, side effects, tolerability and patients' comorbid profiles.

\section{References:}

1) Koenig HG, Blazer DG. Depression, anxiety, and other mood disorders. In: Casse CK, Leipzig RM, Cohen HJ, et al, editors. Geriatric medicine: an evidence-based approach. 4th edition. New York: Springer-Verlag; 2003. 1163-1183

2) Singh $T B$, Singh SG, Mhetre BB, Pangkam M. Late onset depression: Issues in clinical care. J Med Soc.2013; 27: 87-89.

3) Ismail Z, Fischer C, McCall V. What Characterizes Late-Life Depression? Psychiatr Clin N Am. 2013: (36): 483-496.

4) Baldwin, R. C. \& O'Brien, J. Vascular basis of late-onset depressive disorder. British Journal of Psychiatry. 2002; 180: 157-160.

5) American Psychological Association. Diagnostic and statistical manual of mental disorders. 5th edition. Washington, DC: American Psychological Association; 2013.

6) Fiske A, Wetherell JL, Gatz M. Depression in Older Adults. Annual review of clinical psychology. 2009; 5: 363-389. doi:10.1146/annurev.clinpsy.032408.153621.

7) Selbaek $G$ and Borza T. Depression in Later Life. In N.A. Pachana (ed.). Encyclopedia of Geropsychology, Singapore: Springer. 2015.

8) Raison CL, Capuron L, Miller AH: Cytokines sing the blues: inflammation and the pathogenesis of major depression. Trend Immunol 2006; $27: 24-31$
9) Kling MA, Alesci S, Csako G, Costello R, Luckenbaugh DA, Bonne O, Duncko R, Drevets WC, Manji HK, Charney DS, Gold PW: Sustained low-grade pro-inflammatory state in unmedicated, remitted women with major depressive disorder as evidenced by elevated serum levels of the acute phase proteins $\mathrm{C}$-reactive protein and serum amyloid A. Biol Psychiatry 2007; 62:309-313.

10) Dantzer R, O'Connor JC, Freund GG, Johnson RW, Kelley KW: From inflammation to sickness and depression: when the immune system subjugates the brain. Nat Rev Neurosci 2008; 9:46-56.

11) Miller $\mathrm{AH}$, Raison $\mathrm{CL}$. Immune System Contributions to the Pathophysiology of Depression. Biol Psychiatry. 2009;65:732-741.

12) Zorilla E, Luborsky L, McKay J, Roesnthal R, Houldin A, Tax A, McCorkle R, Seligman DA, Schmidt K: The relationship of depression and stressors to immunological assays: a meta-analytic review. Brain Behav Immun 2001; 15:199-226

13) Alesci S, Martinez PE, Kelkar S, Ilias I, Ronsaville DS, Listwak SJ, Ayala AR, Licinio J, Gold HK, Kling MA, Chrousos GP, Gold PW: Major depression is associated with significant diurnal elevations in plasma interleukin-6 levels, a shift of its circadian rhythm, and loss of physiological complexity in its secretion: clinical implications. J Clin Endocrinol Metab 2005; 90:2522-2530.

14) Capuron L, Gumnick JF, Musselman DL, Lawson DH, Reemsnyder A, Nemeroff $\mathrm{CB}$, Miller AH: Neurobehavioral effects of interferon-_ in cancer patients: phenomenology and paroxetine responsiveness of symptom dimensions. Neuropsychopharmacology 2002; 26:643-652.

15) Wichers MC, Koek GH, Robaeys G, Praamstra AJ, Maes M: Early increase in vegetative symptoms predicts IFN-_-induced cognitivedepressive changes. Psychol Med. 2005; 35:433-441

16) Heim C, Plotsky PM, Nemeroff CB. Importance of studying the contributions of early adverse experience to neurobiological findings in depression. Neuropsychopharmacology 2004; 29(4):641-8.

17) Nemeroff CB. Neurobiological consequences of childhood trauma. J Clin Psychiatry. 2004;65(Suppl 1):18-28.

18) Wong $M-L$, Kling MA, Munson PJ. Pronounced and sustained central hypernoradrenergic function in mahor depression with melancholic features: relation to hypercortisolism and corticotrophin-releasing hormone. Proc Natl Acad Sci U S A. 2000;97:325-30.

19) Gold PW, Drevets WC, Charney DS. New insights into the role of cortisol and the glucocorticoid receptor in severe depression. Biol Psychiatry 2002;52(5):381-5.

20) Heuser I, Bissette $G$, Dettling $M$, et al. Cerebrospinal fluid concentrations of corticotropin-releasing hormone, vasopressin, and somatostatin in depressed patients and healthy controls: response to amitriptyline treatment. Depress Anxiety. 1998;8(2):71-9.

21) Banki CM, Karmacsi L, Bissette G, et al. CSF corticotropin-releasing hormone and somatostatin in major depression: response to antidepressant treatment and relapse. Eur Neuropsychopharmacol. 1992;2(2):107-113

22) Fitzgerald PB, Laird AR, Maller J, et al. A meta-analytic study of changes in brain activation in depression. Hum Brain Mapp. 2008; 29(6):683-95.

23) Nemeroff $\mathrm{CB}$, Owens MJ. The role of serotonin in the pathophysiology of depression: as important as ever. Clin Chem 2009;55: 12578-9.

24) Evans DL, Charney DS, Lewis L, et al. Mood disorders in the medically ill: scientific review and recommendations. Biol Psychiatry 2005;58:17589.

25) Mallik S, Krumholz HM, Lin ZQ, et al. Patients with depressive symptoms have lower health status benefits after coronary artery bypass surgery. Circulation. 2005;111:271-7.

26) Lesperance F, Frasure-Smith N, Talajic M. Major depression before and after myocardial infarction: its nature and consequences. Psychosom Med. 1996; 58:99-110.

27) Glassman AH, Bigger JT, Gaffney M. Psychiatric characteristics associated with long-term mortality among 361 patients having an acute coronary syndrome and major depression: seven-year follow-up of SADHART participants. Arch Gen Psychiatry. 2009;66(9):1022-9.

28) Schindler AE. Thyroid function and postmenopause. Gynecol Endocrinol. 2003; 17:79.

29) Harman SM, Metter EJ, Tobin JD, et al. Longitudinal effects of aging on serum total and free testosterone levels in healthy men. Baltimore Longitudinal Study of Aging. J Clin Endocrinol Metab. 2001; 86:724.

30) Christo PJ. Opioid effectiveness and side effects in chronic pain [review]. Anesthesiol Clin North America. 2003; 21:699-71 
31) Maurer J, Rebbapragada V, Borson S, et al. Anxiety and depression in COPD: current understanding, unanswered questions, and research needs. Chest 2008;134:43S-56S.

32) Lacasse $Y$, Rousseau L, Maltais F. Prevalence of depressive symptoms and depression in patients with severe oxygen dependent chronic obstructive pulmonary disease. J Cardiopulm Rehabil 2001; 21:80-6.

33) Ewig S, Torres A. Severe community-acquired pneumonia. Clin Chest Med. 1999; 20:575-87.

34) Garvey C. Depression in patients with chronic obstructive pulmonary disease. Postgrad Med. 2012;124(3):101-9.

35) Aziz, R., \& Steffens, D. C. What are the causes of late-life depression? The Psychiatric Clinics of North America.2013;36:497-516.

36) Alexopoulos, G. S. Depression in the elderly.Lancet, 2005; 365, 1961 1970.

37) Ehrt U, Brønnick K, Leentjens AF, et al. Depressive symptom profile in Parkinson's disease: a comparison with depression in elderly patients without Parkinson's disease. Int J Geriatr Psychiatry. 2006; 21(3):2528.

38) McDonald WM, Richard IH, DeLong MR. Prevalence, etiology, and treatment of depression in Parkinson's disease. Biol Psychiatry. 2003; 54(3):363.

39) Marsh L, McDonald WM, Cummings J, et al. Provisional diagnostic criteria for depression in Parkinson's disease: report of an NINDS/NIMH Work Group. Mov Disord. 2005; 21(2):148-58.

40) Variend $H$ and Gopal YV. Late-onset depression: issues affecting clinical care .Advances in Psychiatric Treatment. 2008:14, 152-158.

41) Salzman C. Mood Disorders. The American Psychiatric Press textbook of geriatric neuropsychiatry. C. Edward Coffey, Jeffrey L. Cummings. 2nd edition.

42) Siu AL. The US preventive services task force (USPSTF). Screening for depression in adults: US preventive services task force recommendation statement. JAMA. 2016;315(4):380-7

43) Newman BM. Treatment-Resistant Depression in the Elderly: Diagnostic and Treatment Approaches. Curr Geri Rep. 2016. doi:10.1007/s13670016-0186-5

44) Norman MA, Whooley ME, Kewchang L. Depression and other mental health issues. In: Landefeld CS, Palmer RM, Johnson MA, et al, editors. Current geriatric diagnosis and treatment. New York: Lange Medical Books/McGraw-Hill; 2004. p. 100-13.

45) Shanmugham B, Karp J, Drayer R, et al. Evidence-based pharmacologic interventions for geriatric depression. Psychiatr Clin North Am 2005;28(4):821-35, viii.

46) Colenda CC, Wagenaar DB, Mickus M, et al. Comparing clinical practice with guideline recommendations for the treatment of depression in geriatric patients: findings from the APA practice research network. Am J Geriatr Psychiatry 2003; 11(4):448-57.

47) Gum AM, Arean PA, Hunkeler $E$, et al. Depression treatment preferences in older primary care patients. Gerontologist. 2006;46(1):14-22.

48) Pinquart M, Duberstein PR, Lyness JM. Treatments for later-life depressive conditions: a meta-analytic comparison of pharmacotherapy and psychotherapy.Am J Psychiatry. 2006;163(9):1493-501.

49) Lewinsohn P. A behavioral approach to depression. In: Friedman RJ, Katz MM, editors. The psychology of depression: contemporary theory and research.New York: Wiley; 1974. p. 157-85.

50) Bottino CM, Barcelos-Ferreira R, Ribeiz SR. Treatment of depression in older adults. Curr Psychiatry Rep. 2012;14:289-97.

51) Wagenaar DB, Mickus MA, Gaumer KA, et al. Late-life depression and mental health services in primary care. J Geriatr Psychiatry Neurol. 2002;15:134-40.

52) Bloch $\mathrm{MH}$, Hannestad J. Omega-3 fatty acids for the treatment of depression: systematic review and meta-analysis. Mol Psychiatry. 2012; 17:1272-82.

53) Rondanelli M, Giacosa A, Opizzi A, et al. Effect of omega-3 fatty acids supplementation on depressive symptoms and on health-related quality of life in the treatment of elderly women with depression: a double-blind, placebo-controlled, randomized clinical trial. J Am Coll Nutr. 2010; 29:55-64.

54) Mischoulon D, Raab MF. The role of folate in depression and dementia. J Clin Psychiatry. 2007;68(Suppl 10):28-33.

55) Mischoulon D, Fava M, Stahl S. Folate supplementation [response to letter]. J Clin Psychiatry. 2009;70:767-9.
56) Papakostas GI, Shelton RC, Zajecka JM, et al. I-Methylfolate as adjunctive therapy for SSRI-resistant major depression: results of two randomized, doubleblind, parallel-sequential trials. Am J Psychiatry. 2012; 169:1267-74

57) Warburton DE, Nicol CW, Bredin SS. Health benefits of physical activity: the evidence. CMAJ. 2006; 174:801-9.

58) Strawbridge WJ, Deleger $S$, Roberts RE, et al. Physical activity reduces the risk of subsequent depression for older adults. Am J Epidemiol 2002;156: 328-34.

59) Kodis J, Smith KM, Arthur HM, et al. Changes in exercise capacity and lipids after clinic versus home-based aerobic training in coronary artery bypass graft surgery patients. J Cardiopulm Rehabil. 2001;21:31-6.

60) Fukukawa $Y$, Nakashima C, Tsuboi S, et al. Age differences in the effect of physical activity on depressive symptoms. Psychol Aging. 2004;19:346-51.

61) Mukai Y, Tampi RR. Treatment of depression in the elderly: a review of the recent literature on the efficacy of single- versus dual-action antidepressants. Clin Ther. 2009;31:945-61.

62) Logan IC, Witham MD. Efficacy of treatment for orthostatic hypotension a systematic review. Age Ageing. 2012;41:587-94

63) Kugaya A, Sanacora G. Beyond monoamines: glutamatergic function in mood disorders. CNS Spectr2005; 10: 808-819.

64) Pittaluga A, Raiteri L, Longordo F, et al. Antidepressant treatments and function of glutamate ionotropic receptors mediating amine release in hippocampus. Neuropharmacology 2007; 53: 27-36.

65) Moghaddam B, Jackson M. Effect of stress on prefrontal cortex function Neurotox Res 2004; 6:73 78

66) Sapolsky RM. The possibility of neurotoxicity in the hippocampus in major depression: a primer on neuron death. Biol Psychiatry 2000; 48: 755-765.

67) Bhagwagar Z, Wylezinska M, Jezzard P, et al. Reduction in occipital cortex gamma-aminobutyric acid concentrations in medication-free recovered unipolar depressed and bipolar subjects. Biol Psychiatry 2007; 15:61: 806-812.

68) Skolnick P. Antidepressants for the new millennium. Eur J Pharmacol 1999; 375: 31-40.

69) Berman RM, Cappiello A, Anand A, et al. Antidepressant effects of ketamine in depressed patients. Biol Psychiatry 2000; 47: 351-354.

70) Olney JW. Neurotoxicity of NMDA receptor antagonists: an overview. Psychopharmacol Bull 1994; 30: 533-540.

71) Corti C, Battaglia G, Molinaro G, et al. The use of knock-out mice unravels distinct roles for mGlu2 and mGlu3 metabotropic glutamate receptors in mechanisms of neurodegeneration/neuroprotection. J Neurosci 2007; 27: 8297-8308.

72) Palucha A, Pilc A. Metabotropic glutamate receptor ligands as possible anxiolytic and antidepressant drugs. Pharmacol Ther 2007; 115: 116147.

73) Witkin JM, Marek GJ, Johnson BG, Schoepp DD. Metabotropic glutamate receptors in the control of mood disorders. CNS Neurol Disord Drug Targets 2007; 6: 87-100.

74) Palucha A, Pilc A. Metabotropic glutamate receptor ligands as possible anxiolytic and antidepressant drugs. Pharmacol Ther 2007; 115: 116 147.76. Witkin JM, Marek GJ, Johnson BG, Schoepp DD. Metabotropic glutamate receptors in the control of mood disorders. CNS Neurol Disord Drug Targets 2007; 6: 87-100.

75) Benavides J, Camelin JC, Mitrani N, et al. 2-Amino-6- trifluoromethoxy benzothiazole, a possible antagonist of excitatory amino acid neurotransmission-II. Biochemical properties. Neuropharmacology 1985; 24: 1085-1092.

76) Coric V, Milanovic S, Wasylink S, et al. Beneficial effects of the antiglutamatergic agent riluzole in a patient diagnosed with obsessivecompulsive disorder and major depressive disorder. Psychopharmacology 2003; 167: 219-220.

77) Zarate CA Jr, Payne JL, Quiroz J, et al. An open label trial of riluzole in patients with treatment resistant major depression. Am J Psychiatry 2004; 161: 171-174.

78) Sanacora G, Kendell SF, Levin Y, et al. Preliminary evidence of riluzole 
efficacy in antidepressant-treated patients with residual depressive symptoms. Biol Psychiatry 2007; 61: 822-825.

79) Pandi-Perumal SR, Zisapel N, Srinivasan V, Cardinali DP. Melatonin and sleep in aging population. Exp Gerontol 2005; 40: 911-925.

80) Srinivasan $V$, Smits $M$, Spence $W$, et al. Melatonin in mood disorders. World J Biol Psychiatry 2006; 7: 138-151.

81) Wetterberg L, Bergiannaki JD, Paparrigopoulos T, et al. Normative melatonin excretion: a multinational study. Psychoneuroendocrinology 1999; 24: 209-226.

82) Dolberg OT, Hirschmann S, Grunhaus L. Melatonin for the treatment of sleep disturbances in major depressive disorder. Am J Psychiatry 1998; 155:1119-1121.

83) Banasr $M$, Soumier A, Hery $M$, et al. Agomelatine, a new antidepressant, induces regional changes in hippocampal neurogenesis. Biol Psychiatry 2006; 59:1087-1096.

84) Montgomery SA, Kasper S. Severe depression and antidepressants: focus on a pooled analysis of placebo-controlled studies on agomelatine. Int ClinPsychopharmacol 2007; 22: 283-291.

85) Stotz G., B. Woggon, J. Angst, Psychostimulants in the therapy of treatment- resistant depression Review of the literature and findings from a retrospective study in 65 depressed patients, Dialogues Clin. Neurosci. 1 (1999) 165-174.

86) P. Skolnick, P. Popik, A. Janowsky, B. Beer, A.S. Lippa, Antidepressant-like actions of DOV 21,947: a triple reuptake inhibitor, Eur. J. Pharmacol. 2003; 461 99-104.

87) Learned S., O. Graff, S. Roychowdhury, R. Moate, K.R. Krishnan, G. Archer, et al., Efficacy, safety, and tolerability of a triple reuptake inhibitor GSK372475 in the treatment of patients with major depressive disorder: two randomized, placeboand active-controlled clinical trials, J. Psychopharmacol. (Oxf.) 2012; 26 653-662.

88) Zhang R., X. Li, Y. Shi, Y. Shao, K. Sun, A. Wang, et al., The effects of LPM570065, a novel triple reuptake inhibitor, on extracellular serotonin, dopamine and norepinephrine levels in rats, PLOS ONE 2014; e91775.

89) Y.S. Mineur, M.R. Picciotto, Nicotine receptors and depression: revisiting and revising the cholinergic hypothesis, Trends Pharmacol. Sci. 2010. ; 580-586.

90) Vieta E., M.E. Thase, D. Naber, B. D'Souza, E. Rancans, U. Lepola, et al., Efficacy and tolerability of flexibly-dosed adjunct TC-5214 (dexmecamylamine) in patients with major depressive disorder and inadequate response to prior antidepressant, Eur. Neuropsychopharmacol.: J. Eur. Coll. Neuropsychopharmacol. 2014; 24 564-574.

91) A.T. Knoll, W.A. Carlezon Jr., Dynorphin, stress, and depression, Brain Res. 2010. $1314 ;$ 56-73.

92) Bay-Richter C., K.R. Linderholm, C.K. Lim, M. Samuelsson, L. Traskman-Bendz, G.J. Guillemin, et al., A role for inflammatory metabolites as modulators of the glutamate $\mathrm{N}$-methyl-d-aspartate receptor in depression and suicidality, Brain Behav. Immun. 2015; 43 110-117.

93) Muller N., M.J. Schwarz, S. Dehning, A. Douhe, A. Cerovecki, B. Goldstein-Muller, et al., The cyclooxygenase-2 inhibitor celecoxib has therapeutic effects in major depression: results of a double-blind, randomized, placebo controlled, add-on pilot study to reboxetine, Mol. Psychiatry .2006; 11: 680-684

94) Akhondzadeh S., S. Jafari, F. Raisi, A.A. Nasehi, A. Ghoreishi, B. Salehi, et al., Clinical trial of adjunctive celecoxib treatment in patients with major depression: a double blind and placebo controlled trial, Depress. Anxiety. 2009; 26: 607-611.

95) Abbasi S.H., F. Hosseini, A. Modabbernia, M. Ashrafi, S. Akhondzadeh, Effect of celecoxib add-on treatment on symptoms and serum IL-6 concentrations in patients with major depressive disorder: randomized double-blind placebocontrolled study, J. Affect. Disord. 2012; 141: 308 314.

96) Johansson D., A. Falk, M.M. Marcus, T.H. Svensson, Celecoxib enhances the effect of reboxetine and fluoxetine on cortical noradrenaline and serotonin output in the rat, Prog. Neuropsychopharmacol. Biol. Psychiatry.2012; 39: 143-148.

97) Raison C.L., R.E. Rutherford, B.J. Woolwine, C. Shuo, P. Schettler, D.F. Drake, et al., A randomized controlled trial of the tumor necrosis factor antagonist infliximab for treatment-resistant depression: the role of baseline inflammatory biomarkers, JAMA Psychiatry. 2013: 70 31-41. 